\title{
The Effects of Thermo-Physical Parameters on Free Convective Flow of a Chemically Reactive Power Law Fluid Driven by Exothermal Plate
}

\author{
Damilare John Samuel*, Babatunde Oluwaseun Ajayi \\ Department of Mathematical Sciences, Federal University of Technology, Akure, Nigeria \\ Email address: \\ samueldj009@yahoo.com (D. J. Samuel), atundeoluwaseun ayahoo.com (B. O. Ajayi) \\ ${ }^{*}$ Corresponding author
}

To cite this article:

Damilare John Samuel, Babatunde Oluwaseun Ajayi. The Effects of Thermo-Physical Parameters on Free Convective Flow of a Chemically Reactive Power Law Fluid Driven by Exothermal Plate. Chemical and Biomolecular Engineering. Vol. 3, No. 3, 2018, pp. 22-34. doi: $10.11648 /$ j.cbe.20180303.12

Received: August 28, 2018; Accepted: September 14, 2018; Published: October 22, 2018

\begin{abstract}
In this article, the effects of thermo-physical parameters on free convective flow of a chemically reactive power law fluid driven by exothermal plate is studied. The effect of thermal radiation on the fluid flow is investigated. Also, an exothermal surface reaction modeled by Arrhenius kinetics supplied heat to the power law fluid. Suitable similarity transformations are used to transform the non-linear partial differential equations into system of non-linear coupled ordinary differential equations. The obtained coupled non-linear ordinary differential equations are then solved numerically via fourthorder Runge-Kutta Fehlberg method. A parametric study is performed to illustrate the influence of thermal conductivity parameter, Grashof number, power-law index, velocity exponent parameter, Prandtl number, heat generation parameter, magnetic parameter, Eckert number, radiation parameter, Frank-Kamenetskii parameter, activation energy parameter, Brinkman number, reactant consumption parameter, and suction parameter on the fluid velocity and temperature profiles within the boundary layer. Numerical values of different controlling parameters for local skin friction coefficient and local Nusselt number are obtained and discussed. Comparison of the present work with existing literature was carried out and the results are in excellent agreement. The results also shows that skin friction coefficient decreases with increase in Eckert number, while the rate of heat transfer is enhanced at the surface of the plate as the Eckert number increase.
\end{abstract}

Keywords: Power Law Fluid, Viscous Dissipation, Natural Convection Heat Transfer, Fehlberg Method, Thermal Radiation

\section{Introduction}

In recent times, the study of non-Newtonian fluid flow and heat transfer over a stretching surface has gained interest in many fields of science and technology due to its variety of engineering applications in the movement of biological fluids, manufacturing of plastic sheets, performance of lubricants, drilling muds and food processing. Unlike Newtonian fluid where the relation between the shear stress and the shear rate is linear, the constitutive equation of nonNewtonian fluids does not follow the linear relationship between stress and the rate of strain. As a result of these differences, quite a lot of mathematical expressions of varying complexity and form have been proposed in the literature to model non-Newtonian fluids [1-5], keeping in view their numerous rheological characteristics. One of such model is the power-law fluid which is the simplest and the most common model. Because of wide range of applications, studies on power-law fluid have gained more attention. The relationship between shear stress and shear rate for this type of fluid can be mathematically expressed as follows [1]:

$$
\begin{aligned}
& \tau_{y x}=K\left(\dot{\tau}_{y x}\right)^{n} \\
& \mu=K\left(\dot{\tau}_{y x}\right)^{n-1}
\end{aligned}
$$

where $\mathrm{K}$ and $\mathrm{n}$ are two empirical curve-fitting parameters and are known as the fluid consistency coefficient and the powerlaw index of the fluid, respectively. This fluid model is 
capable of describing the characteristics of the pseudo-plastic and dilatant behavior of the fluid. The fluid is said to be pseudo plastic or exhibits shear thinning properties when $\mathrm{n}<1$, the fluid is called dilatant or exhibits shear thickening; for $n>1$, while it shows Newtonian behavior when $n=1$. The study of natural convection of non-Newtonian power-law fluids began with Acrivos [6]. After this, various aspects of natural convective flow problem involving non-Newtonian power-law fluids have been extensively studied by several authors. Tien [7] examined the laminar natural convection heat transfer between a vertical plate and a power-law fluid. Approximate solutions were gotten with high Prandtl number via an integral method. Som and Chen [8] analyzed the free convection heat transfer in power law non-Newtonian fluids from a two dimensional (2-D) body. In their work, they consider cases where the surface is subject to power-law variations in (i) temperature and (ii) heat flux. Natural convection of a laminar two-dimensional boundary-layer flow of non-Newtonian fluids over a horizontal circular cylinder with the heating condition of uniform surface heat flux has been studied by Bhowmick and Molla [9]. They obtained new similarity reductions and found a numerical solution by using marching order implicit finite difference method with double sweep technique. Bognár et al. [10] presented an analytical solution for the velocity profiles of a layer of liquid flowing on an inclined moving plane. They reported that the maximum values of the velocity decrease as power-law index $\mathrm{n}$ increases. Pantokratoras [11] examined numerically a natural convective flow along a vertical isothermal plate in a non-Newtonian power-law fluid. On the other hand, Olajuwon [12] have included the heat generation effect to the non-Newtonian power-law convective fluid flow problems and solved the problems numerically using Runge - Kutta shooting method. Their analysis showed that the skin friction increases with increase in the heat generation parameter and the Nusselt number decreases with increase in the heat generation parameter.

All the aforementioned works do not put hydromagnetic effects into consideration, but in recent decades, quite a lot of industrial processes have dealt with power law fluid flow with magnetic fields. Because of this fact, some researchers have advanced this field. From industrial point of view, the study of hydrodynamics fluid flow over a stretching sheet is of great important. Specifically in nuclear engineering control, plasma aerodynamics, mechanical engineering, manufacturing processes, astrophysical fluid dynamics and magnetohydrodynamic (MHD) energy systems, In view of the applications of MHD, Pavlov [13] made the first move to investigate the MHD boundary layer flow of an electrically conducting fluid over a stretching wall. In recent years, Darji and Timol [14] applied deductive group symmetry method to derive similarity transformations for the natural convective boundary layer flow of a class of non-Newtonian fluids to ordinary differential system for the class of Non-Newtonian fluids. Shahzad and Ali [15] investigated the MHD flow and heat transfer of a power-law fluid on a vertical stretching sheet using convective thermal boundary conditions.
Appropriate similarity transformations is used to reduce the governing coupled partial differential equation to nonlinear ordinary differential equations. They found analytic solutions of the reduced equations via HAM, they reported that the boundary layer thickness decreases as the power-law index $n$ increases.

Ahmed et al. [16] investigated the laminar MHD boundary layer flow of power law fluid over an unsteady porous radially stretching sheet in the presence of convective boundary conditions. Using similarity transformations governing partial differential equations were reduced to ordinary differential equations. They investigated the solutions of the governing problem for the velocity and temperature fields analytically using HAM and numerically by shooting technique. It was noticed that the effect of magnetic parameter $\mathrm{M}$ on velocity profile become less dominating with an increasing values of power law index $n$. The problem of magneto-hydrodynamic flow and heat transfer of an electrically conducting non-Newtonian powerlaw fluid past a non-linearly stretching sheet was studied theoretically by Prasad et al. [17]. They reported that increasing value of magnetic parameter $\mathrm{Mn}$ results in flattering the horizontal velocity profiles and advance the temperature profile.

Thermal radiation is of significant interest in the processes where high temperature is evoked, for instance, glass production, furnace design and in space technology applications such as cosmical flight aerodynamics rocket, nuclear plants etc. It is well known that thermal radiation has been widely studied experimentally and numerically due to great significant applications in the design of various propulsion devices or aircraft, gas turbines, missiles, satellites and space vehicles. Due to the practical importance of thermal radiation considerable research has been devoted by various authors to advance this topic. Kishan and Kavitha [18] have investigated the boundary layer flow of a nonNewtonian magneto-hydrodynamic of an electrically conducting power law fluid flowing over a non-linear stretching surface in the presence of thermal radiation, taking into account the viscous dissipation effects. It was reported that increasing value of velocity exponent $\mathrm{m}$ decrease the velocity profile and temperature profile, respectively, for the case of Pseudo plastic fluids (0.8), Newtonian fluids $(n=1)$ and dilatant fluids $(n=1.6)$. Saritha et al. [19] investigated radiation effects on MHD non-Newtonian power-law fluid past a non-linearly stretching surface with viscous dissipation. They showed in their plots that increase in radiation parameter leads to increase in the temperature profile for both Newtonian and non-Newtonian fluids. As a result of this, the thermal boundary layer thickness increases with radiation. The effect of thermal radiation on unsteady gravity flow of a power-law fluid with viscous dissipation through a porous medium was studied by Ogunsola and Peter [20]. Very recently, Ahmed et al. [21] analyzed the steady state, two-dimensional, boundary layer flow of a power law fluid over a porous moving flat plate in the presence of the thermal radiation, viscous dissipation and internal heat 
generation or absorption. They reported the existence of dual solutions when the flat plate and the free stream move in opposite directions. Samuel [22] investigated the analytical solution for chemical reaction and melting heat transfer effects on MHD steady two-dimensional laminar viscous incompressible radiating boundary layer flow over a flat plate in the presence of variable fluid properties and Soret effect. It was reported that the temperature decreases as the thermal radiation and melting parameter increase.

The purpose of this article is to carry out a numerical study on MHD free convection flow of optically thin radiating, incompressible, electrically conducting and reactive fluid past an infinite plate taking into account the combined effects of thermal radiation, viscous dissipation, variable thermal conductivity and ohmic heating. There is an exothermic surface reaction characterized by first order non-isothermic reaction called Arrhenius kinetics on the plate Khan [23]. We also consider that heat is being generated to the power law fluid due to exothermic surface reaction. This type of flow found applications in chemical engineering, geothermal or oil reservoir engineering [24]. The boundary layer equations for the conservation of momentum and energy have been reduced to coupled nonlinear ordinary differential equations using suitable similarity variables and solved numerically via Runge-Kuta Felbheg method. The effects of thermal conductivity parameter $\Lambda$, Grashof number $G_{r}$, power-law index $\mathrm{n}$, velocity exponent parameter $\mathrm{m}$, Prandtl number $P_{r}$, heat generation parameter $\mathrm{S}$, magnetic parameter $\mathrm{M}$, Eckert number $E_{c}$, radiation parameter $R_{a}$, Frank-Kamenetskii parameter $\delta$, activation energy parameter $\mathcal{E}$, Brinkman number $B_{r}$, reactant consumption parameter $\Omega$, and local suction or injection parameter $f_{w}$ on flow field and heat transfer are graphically discussed.

\section{Problem Formulation}

Consider a steady, laminar, incompressible, twodimensional boundary layer flow of a non-Newtonian powerlaw optically thin radiating fluid past an exothermic surface in the presence of a transverse magnetic field $B_{0}$. The xcoordinate is taken along the plate and $y$-coordinate is measured normal to the surface of the plate as shown in Figure 1. The continuous stretching plate is assumed to have a non-linear velocity of the form $U(x)=b x^{m}$, where $\mathrm{b}$ is a constant and $\mathrm{m}$ is velocity exponent. The flow is generated as a result of non-linear stretching of the boundary sheet. Cogley et al. [25] is used to describe the radiative heat flux in the energy equation. The viscous dissipation effect is taken into consideration in the energy equation. Following Merkin et al. [26], the exothermic surface reaction is assumed to generate heat to the viscous fluid and it is modeled by first order non-isothermal reaction which is shown below:

$$
A \rightarrow B+\text { Heat, rate }=A_{0} C e^{-\frac{E}{R T}} .
$$

The above expression is called Arrhenius kinetics where E is activation energy, $\mathrm{B}$ is product species, $\mathrm{R}$ is the universal gas constant, $A_{0}$ is the rate constant, $\mathrm{C}$ is the concentration of reactant $\mathrm{A}$ and $\mathrm{T}$ is the temperature. The heat generated by the surface reaction result in a convective flow close to the surface. Based on the aforementioned assumptions coupled with Boussinesq approximations, the resulting equations governing the flow and heat transfer are

$$
\begin{gathered}
\frac{\partial u}{\partial x}+\frac{\partial v}{\partial y}=0, \\
u \frac{\partial u}{\partial x}+v \frac{\partial u}{\partial y}=\frac{\mu}{\rho} \frac{\partial}{\partial y}\left(-\frac{\partial u}{\partial y}\right)^{n}+g \beta\left(T-T_{\infty}\right)-\frac{\sigma B_{0}^{2}}{\rho} u, \\
u \frac{\partial T}{\partial x}+v \frac{\partial T}{\partial y}=\frac{1}{\rho c_{p}} \frac{\partial}{\partial y}\left(k_{f} \frac{\partial T}{\partial y}\right)+\frac{\mu}{\rho c_{p}}\left(\frac{\partial u}{\partial y}\right)^{2}-\frac{1}{\rho c_{p}} \frac{\partial q_{r}}{\partial y} \\
+\frac{Q_{s}\left(T-T_{\infty}\right)}{\rho c_{p}}+\frac{\sigma B_{0}^{2}}{\rho c_{p}} u^{2}+\frac{Q C_{0} A_{0}}{\rho c_{p}}\left(\frac{T}{T_{\infty}}\right)^{r} e^{-\frac{E}{R T}}=0,
\end{gathered}
$$

subject to the following boundary conditions:

$$
\begin{gathered}
y=0: u=U(x)=b x^{m}, v=-v_{w}, k_{\infty} \frac{\partial T}{\partial y}=-Q C_{0} A e^{-\frac{E}{R T}}, \\
y \rightarrow \infty: u \rightarrow 0, T \rightarrow T_{\infty},
\end{gathered}
$$

where $\mathrm{u}$ and $\mathrm{v}$ are the velocity components in the $\mathrm{x}$ and $\mathrm{y}$ directions, respectively, $\rho$ the fluid density, $\mathrm{T}$ the fluid temperature, $c_{p}$ the specific heat capacity of the fluid at constant pressure, the radiative heat flux $q_{r}, Q_{s}$ the heat generation or absorption coefficient, $T_{\infty}$ the free stream temperature, $\mu$ the dynamic viscosity, $\beta$ is thermal expansion coefficient, $g$ is the acceleration due to gravity, $\mathrm{Q}$ is the heat of reaction, $C_{0}$ is the initial concentration of the reactant species, $\mathrm{b}$ is a positive constant, $U(x)$ is the surface velocity, $\mathrm{v}_{\mathrm{w}}$ is the normal velocity at the surface having negative value for blowing and positive for suction.

In this study, the fluid thermal conductivity used is a linear function of temperature in the form [24]

$$
k_{f}=k_{\infty}\left[1+\xi\left(T-T_{\infty}\right)\right],
$$

which can also be rewritten as shown below

$$
k_{f}=k_{\infty}(1+\Lambda \theta),
$$

where $k_{f}$ denotes the fluid thermal conductivity, $\Lambda=\frac{\xi R T_{\infty}^{2}}{E}$ is the thermal conductivity parameter, $k_{\infty}$ is the fluid free stream thermal conductivity and $\xi$ is a constant depending on the nature of the fluid, $\theta$ is a dimensionless temperature.

Following Cogley [25] and assuming that the fluid is optically thin with relatively low density, then 


$$
\frac{\partial q_{r}}{\partial y}=4 \gamma^{2}\left(T-T_{\infty}\right)
$$

where $\gamma$ is the mean radiation absorption coefficient, which is given by the following integral,

$$
\gamma^{2}=\int_{0}^{\infty} K_{\lambda}\left(\partial e_{b \lambda} / \partial T\right) d \lambda
$$

$\lambda$ is the wave length, $K_{\lambda}$ is the absorption coefficient, and $e_{b \lambda}$ is the Planck function.

We introduce the stream function $\psi$, where $u=\frac{\partial \psi}{\partial y}$ and $v=-\frac{\partial \psi}{\partial x}$, which satisfies the continuity equation identically. Using similarity variables of the form

$$
\begin{gathered}
\eta=\frac{y}{x}\left(\operatorname{Re}_{x}\right)^{\frac{1}{n+1}}, \theta(\eta)=\frac{E\left(T-T_{\infty}\right)}{R T_{\infty}^{2}}, \\
\psi(x, y)=U x\left(\operatorname{Re}_{x}\right)^{\frac{-1}{n+1}} f(\eta) . \\
n\left(-f^{\prime \prime}\right)^{n-1} f^{\prime^{\prime \prime}}-m \\
\text { the transformed boundary conditions are } \\
(1+\Lambda \theta) \theta^{\prime \prime}+\Lambda\left(\theta^{\prime}\right)^{2}+P_{r}\left(\frac{2 m n-m+1}{n+1}\right) \theta^{\prime} f+ \\
y=0: f(0)=f_{w}, f^{\prime}(0)=1, \theta^{\prime}(0)=-\Omega e^{\frac{\theta}{1+\varepsilon \theta}}, \\
y \rightarrow \infty: f^{\prime}(\infty)=0, \theta(\infty)=0
\end{gathered}
$$$$
n\left(-f^{\prime \prime}\right)^{n-1} f^{\prime \prime \prime}-m\left(f^{\prime}\right)^{2}+\left(\frac{2 m n-m+1}{n+1}\right) f f^{\prime \prime}+G r \theta-M f^{\prime}=0
$$$$
(1+\Lambda \theta) \theta^{\prime \prime}+\Lambda\left(\theta^{\prime}\right)^{2}+P_{r}\left(\frac{2 m n-m+1}{n+1}\right) \theta^{\prime} f+P_{r}\left[S \theta+M E_{c}\left(f^{\prime}\right)^{2}-R_{a} \theta\right]+\delta(1+\varepsilon \theta)^{r} e^{\frac{\theta}{1+\varepsilon \theta}}+B_{r}\left(f^{\prime \prime}\right)^{2}=0
$$

where prime denotes the derivative with respect to the similarity variable and the thermo physical dimensionless parameters in (13)-(16) are defined as follows:

$$
\begin{gathered}
\Lambda=\frac{\xi R T_{\infty}^{2}}{E}, G_{r}=\frac{g \beta R T_{\infty}^{2}}{E b^{2} x^{2 m-1}}, P_{r}=\frac{\rho c_{p} U x}{k_{\infty}\left(\mathrm{Re}_{x}\right)^{2 / n+1}}, \\
S=\frac{Q_{s} x}{\rho c_{p} U}, M=\frac{\sigma B_{0}^{2}}{\rho b x^{m-1}}, E_{c}=\frac{E U^{2}}{R c_{p} T_{\infty}^{2}}, R_{a}=\frac{4 \gamma^{2} x}{\rho c_{p} b x^{m-1}}, \\
\delta=\frac{Q C_{0} A_{0} E x^{2}}{k_{\infty} R T_{\infty}^{2}\left(\operatorname{Re}_{x}\right)^{2 / n+1}} e^{-\frac{E}{R T_{\infty}}}, \varepsilon=\frac{R T_{\infty}}{E}, B_{r}=\frac{\mu U^{2} E}{R k_{\infty} T_{\infty}^{2}}, \\
\Omega=\frac{Q C_{0} A E x}{k_{\infty} R T_{\infty}^{2}\left(\operatorname{Re}_{x}\right)^{2 / n+1}} e^{-\frac{E}{R T_{\infty}}, \operatorname{Re}_{x}=\frac{U^{2-n} x^{n}}{v}} \\
f_{w}=\left(\frac{n+1}{m n+m+1}\right)\left(\frac{v_{w}}{U\left(\operatorname{Re}_{x}\right)^{-1 / n+1}}\right)
\end{gathered}
$$

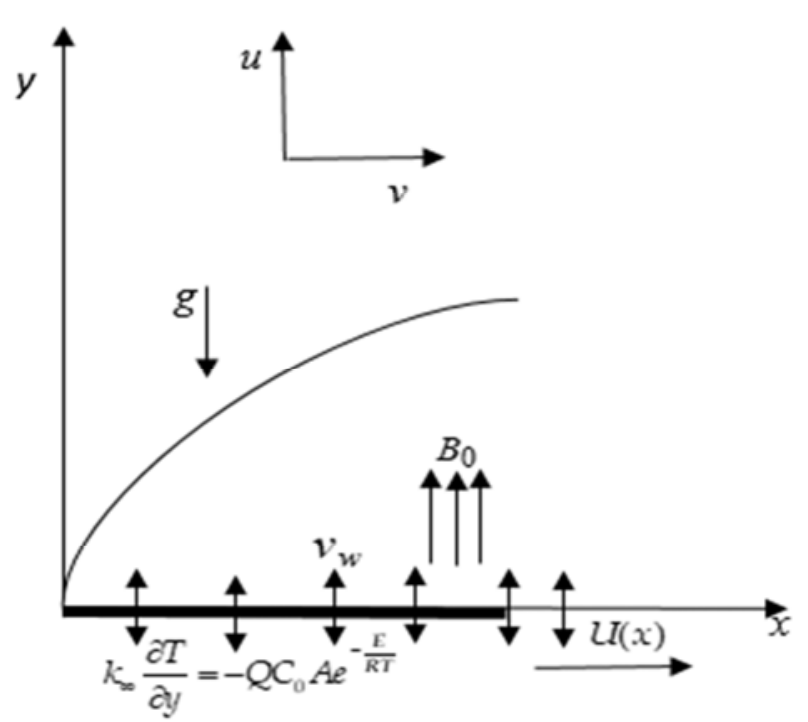

Figure 1. Physical model and coordinate system.

The above transformation reduces the system of partial differential equations into the following system of nonlinear ordinary differential equations: where $\Lambda$ is the thermal conductivity parameter, $G_{r}$ the Grashof number, $P_{r}$ the generalized Prandtl number, $\mathrm{S}$ is the heat generation parameter, $M$ the magnetic parameter, $E_{c}$ the Eckert number, $R_{a}$ the radiation parameter, $\delta$ the FrankKamenetskii parameter, $\varepsilon$ the activation energy parameter, $B_{r}$ the Brinkman number, $\operatorname{Re}_{\mathrm{x}}$ the local generalized Reynolds number, $\Omega$ the reactant consumption parameter, and $f_{w}$ the local suction or injection parameter with suction if $f_{w}>0$, injection if $f_{w}<0$ and impermeable plate when $f_{w}=0$. The quantities of practical interest are the skin friction coefficient $C_{f}$ and the local Nusselt number $N u_{x}$, which are defined as

$$
\begin{gathered}
C_{f}=\frac{\mu\left(\frac{\partial u}{\partial y}\right)_{y=0}}{\rho_{\infty} \mu_{w}^{2} / 2}=2\left(\operatorname{Re}_{x}\right)^{\frac{-1}{n+1}}\left[-f^{\prime \prime}(0)\right]^{n}, \\
N u_{x}=\frac{x\left(\frac{\partial T}{\partial y}\right)_{y=0}}{T_{w}-T_{\infty}}=-\left(\operatorname{Re}_{x}\right)^{\frac{1}{n+1}} \theta^{\prime}(0) .
\end{gathered}
$$




\section{Results and Discussion}

The set of non-linear coupled ordinary differential equations (13)-(14) subject to the boundary conditions (15) and (16) is a two-point boundary value problem (BVP). In order to solve these equations numerically we follow the most efficient numerical shooting technique with a fourthorder Runge-Kutta Fehlberg integration scheme. The effects of the various parameters such as the thermal conductivity parameter $\Lambda$, the Grashof number $G_{r}$, power-law index n, velocity exponent parameter $\mathrm{m}$, the Prandtl number $P_{r}$, the heat generation parameter $\mathrm{S}$, the magnetic parameter $\mathrm{M}$, the Eckert number $E_{c}$, the radiation parameter $R_{a}$, the FrankKamenetskii parameter $\delta$, the activation energy parameter $\mathcal{E}$, the Brinkman number $B_{r}$, the reactant consumption parameter $\Omega$, and the local suction or injection parameter $f_{w}$ on the fluid flow and temperature are shown via tables and graphs. Figures (2) to (22) elucidate the effect of these governing flow parameters for (a) pseudo plastic fluid $(\mathrm{n}<1)$ (b) Newtonian fluid $(\mathrm{n}=1)$ (c) dilatants fluid $(\mathrm{n}>1)$. Figure 2(a-c) shows the effect of Grashof number $G_{r}$ on velocity profiles for (a) pseudo plastic fluid $(\mathrm{n}=0.8)$ (b) Newtonian fluid $(\mathrm{n}=1)$ and (c) dilatants fluid $(\mathrm{n}=1.2)$. It is noticed that the velocity of the fluid increases with the increase of $G_{r}$, because $G_{r}$ signifies the relative effects of thermal buoyancy force to viscous hydrodynamic force in the boundary layer region. This implies that thermal buoyancy force results in the acceleration of fluid flow. Figure 3(a-c) presents the effect of Grashof number on temperature profile. A fall in the temperature profile is observed as the Grashof number increases.

Figure 4(a-c) depicts the effects of heat generation/absorption parameter $\mathrm{S}$ on the temperature profiles. It is observed that the dimensionless temperature $\theta$ increases for increasing strength of the heat generation/absorption parameter. This is due to the fact that heat generation can add more heat to the stretching sheet which then increases its temperature. This result is very much significant for the flow where heat transfer is given prime importance. Figure 5(a-c) elucidates the influence of Prandtl number $P_{r}$ on the temperature profile. It is obvious that an increase in the Prandtl number $P_{r}$ results in a decrease in temperature profiles.

For different values of the Eckert number $E_{c}$, the temperature profile is plotted in Figure 6(a-c) for various values of $E_{c}$. The Figure shows that increasing values of $E_{c}$ heat up the fluid resulting in higher temperatures. This enhancement is due to heat generation in the fluid layers. Figure 7(a-c) and Figure 8(a-c) show the variation of velocity profiles and temperature profiles across the boundary layers for different values of the suction parameter $f_{w}$. As shown in the Figures, increasing values of suction parameter reduces both the velocity profile and temperature profile, respectively.

In Figure 9(a-c), it is noticed that the presence of magnetic field leads to a rapid reduction of velocity in the vicinity of the boundary due to the presence of Lorentz force which opposes the fluid motion. Furthermore, it is noted that increasing the magnetic parameter $\mathrm{M}$ enhances the thermal boundary layer as shown in Figure 10(a-c).

In Figure 11(a-c), the velocity profile has been plotted for different values of velocity exponent parameter $m$, it is observed that the momentum boundary layer thickness reduces as the velocity exponent parameter $\mathrm{m}$ increases. Physically $\mathrm{m}<0$ means that the surface is decelerated from the slot, $\mathrm{m}=0$ implies the continuous momentum of a flat surface while $\mathrm{m}>0$ implies that the surface is accelerated from the extended slit. Also, Figure 12(a-c) portraits the dimensionless temperature for different values velocity exponent parameter $\mathrm{m}$. From the figure, it is seen that the dimensionless temperature profile decreases with increase of velocity exponent parameter $\mathrm{m}$. Figure 13(a-c) illustrates the effect of numerical exponent $\mathrm{r}$ on the temperature profile such that $r=\{-2.0,0,0.5\}$. The numerical exponent $r=0.5$ denotes that the type of exothermic chemical reaction is bimolecular, $r=0$ implies that the type of reaction is Arrhenius and $r=2$ means that the reaction is sensitized. The Figure depicts that less heat is generated under a bimolecular type of exothermic chemical reaction and most heat is generated for sensitized reaction.

The variation of dimensionless temperature profile for various values of thermal conductivity parameter is shown in Figure 14(a-c). It is seen that temperature increases with the increase of thermal conductivity parameter $\Lambda$. It is evident from Figure 15(a-c) that temperature profile decreases as the values of activation energy parameter increase. This is due to the fact that the term $(1+\varepsilon \theta)^{r} e^{\theta / 1+\varepsilon \theta}$ in the energy equation decreases with increasing $\mathcal{E}$ for the value of numerical exponent $\mathrm{r}<0$. Figure 16(a-c) illustrates the effect of radiation on the temperature in the thermal boundary layer. The graph shows a decrease in the temperature of the fluid as the radiation parameter increases, this is because the fluid is emitting heat to the plate as result of radiation effect. As a result of decrease of the fluid temperature, the fluid become more viscous. Hence, the velocity of the fluid reduces as the thermal radiation parameter increases as shown in Figure $17(\mathrm{a}-\mathrm{c})$. 

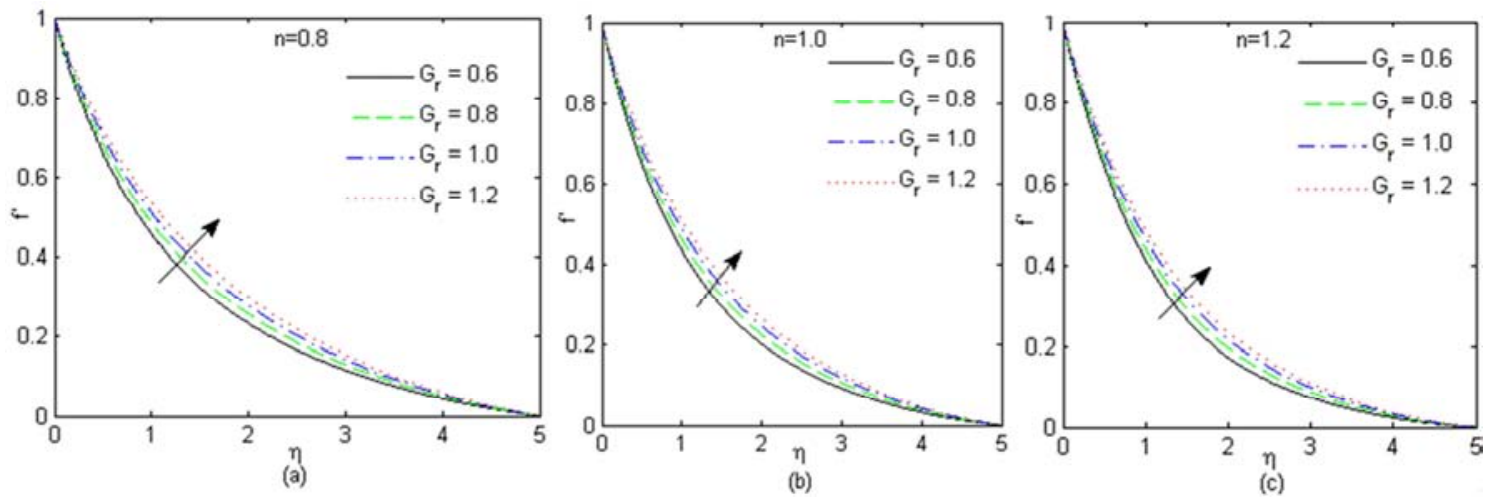

Figure 2. Velocity profiles for different values of $G_{r}$ for $E_{c}=0.5, P_{r}=1.0, m=1.0, r=-2.0, S=0.5, R_{a}=1.0, B_{r}=0.5, M=\delta=\varepsilon=\Lambda=f_{w}=\Omega=0.1$.

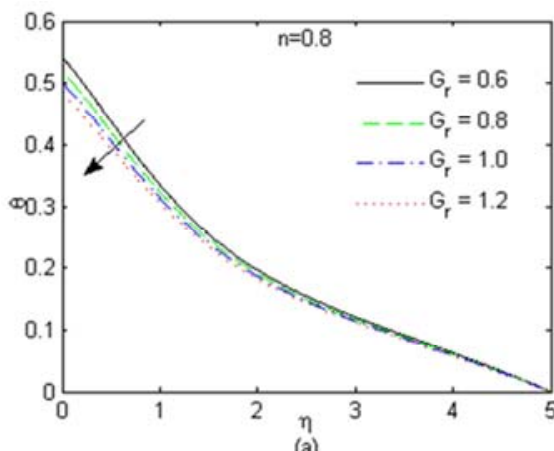

(a)

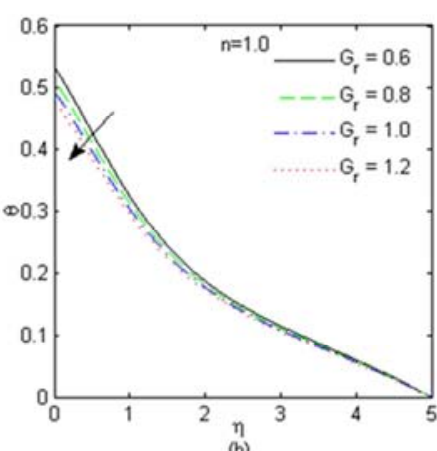

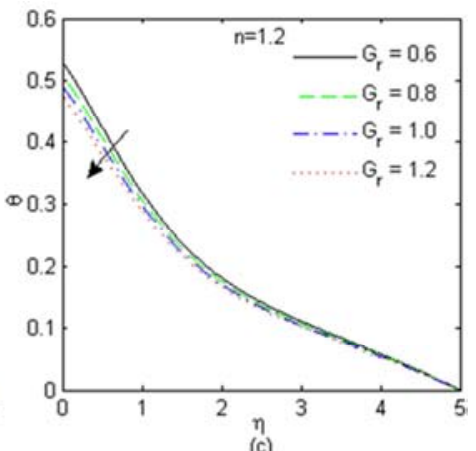

Figure 3. Temperature profiles for different values of $G_{r}$ for $E_{c}=0.5, \quad P_{r}=1.0, \quad m=1.0, \quad r=-2.0, \quad S=0.5, \quad R_{a}=1.0, \quad B_{r}=0.5$, $M=\delta=\varepsilon=\Lambda=f_{w}=\Omega=0.1$.

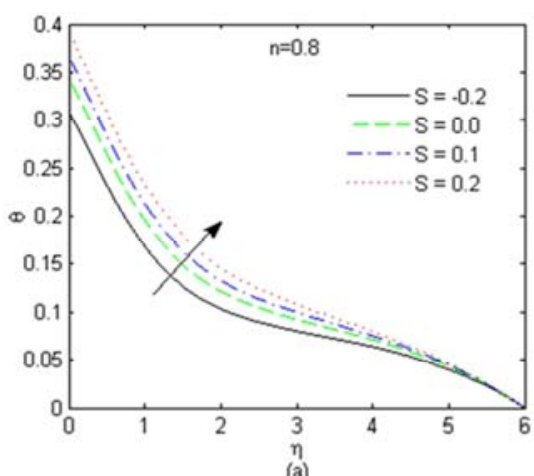

(a)

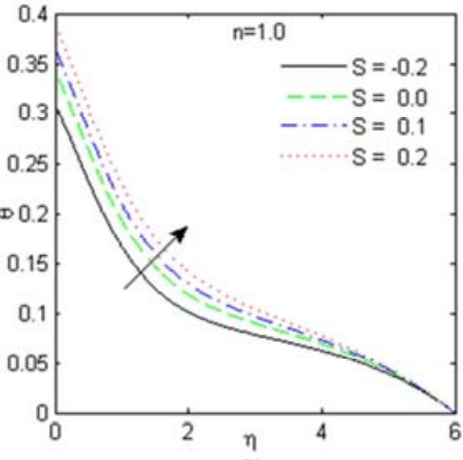

(b)

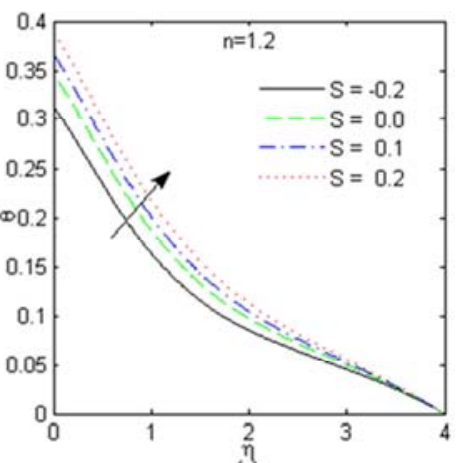

(c)

Figure 4. Temperature profiles for different values of $S$ for $E_{c}=0.5 ; P_{r}=1.0, m=1.0, r=-2.0, P_{r}=1.0, R_{a}=1.0, B_{r}=0.5, M=\delta=\varepsilon=\Lambda=f_{w}=\Omega=0.1$.
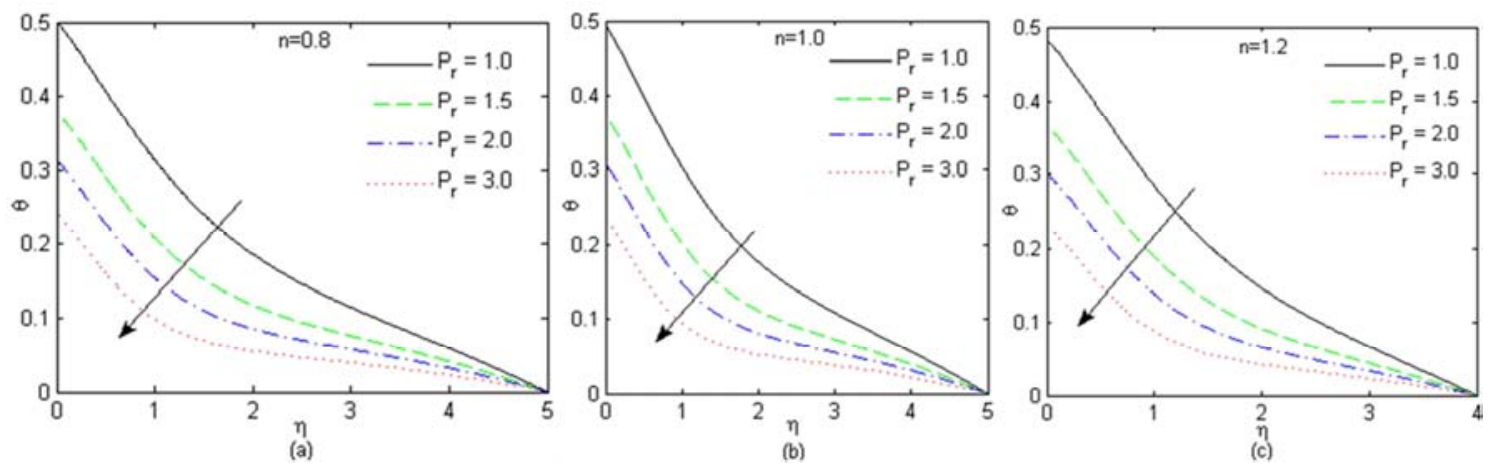

Figure 5. Temperature profiles for different values of $P_{r}$ for $E_{c}=0.5, G_{r}=1.0, m=1.0, r=-2.0, S=0.5, R_{a}=1.0, B_{r}=0.5, M=\delta=\varepsilon=\Lambda=f_{w}=\Omega=0.1$. 

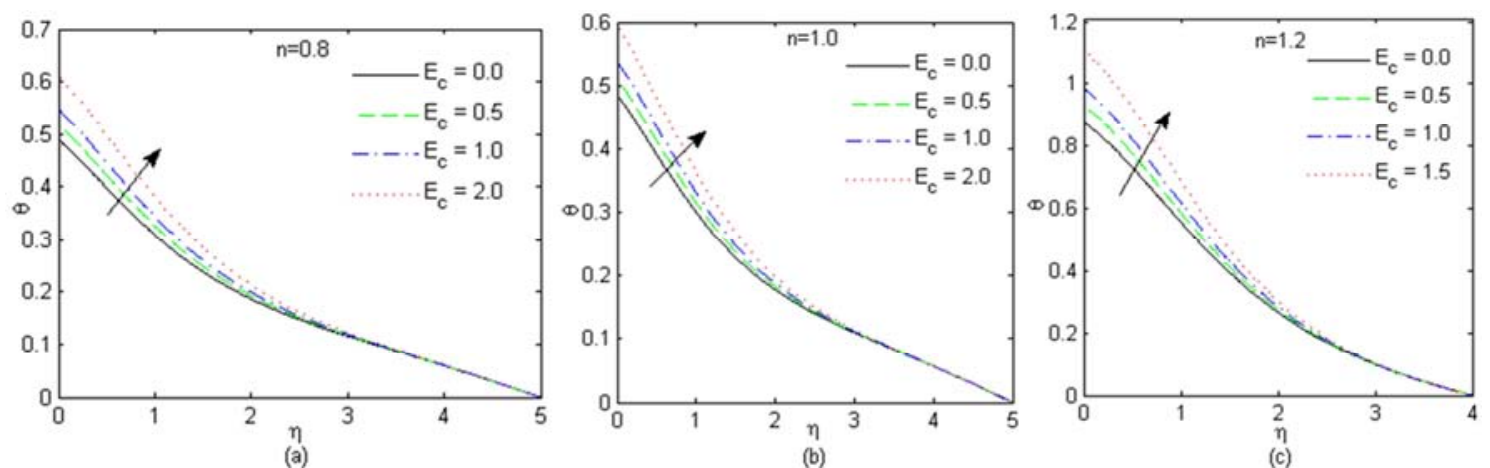

Figure 6. Temperature profiles for different values of $E_{c}$ for $P_{r}=1.0, G_{r}=1.0, m=1.0, r=-2.0, S=0.5, R_{a}=1.0, B_{r}=0.5, M=\delta=\varepsilon=\Lambda=f_{w}=\Omega=0.1$.

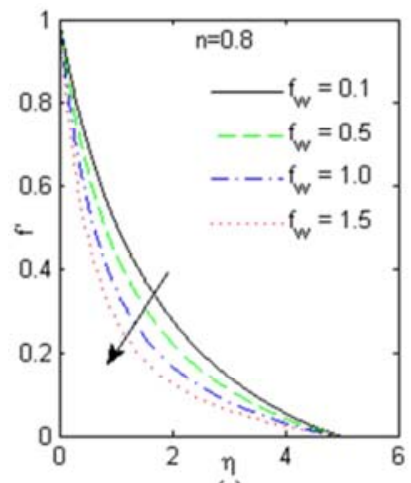

(a)

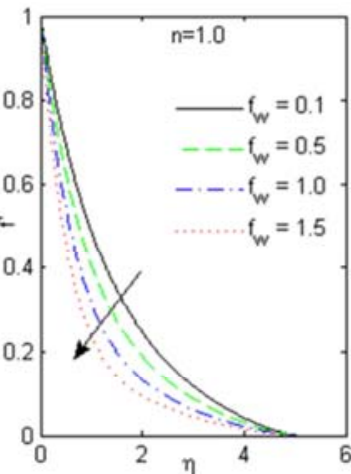

(b)

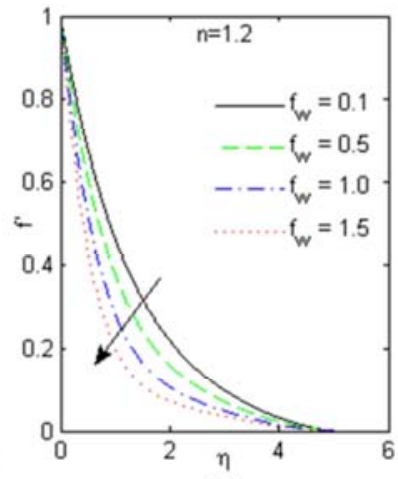

(c)

Figure 7. Velocity profiles for different values of $f_{w}$ for $E_{c}=0.5, P_{r}=1.0, m=1.0, G_{r}=1.0, r=-2.0, S=0.5, R_{a}=1.0, B_{r}=0.5, M=\delta=\varepsilon=\Lambda=\Omega=0.1$.

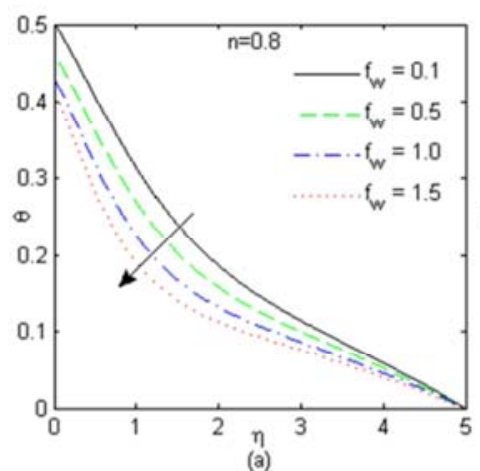

(a)

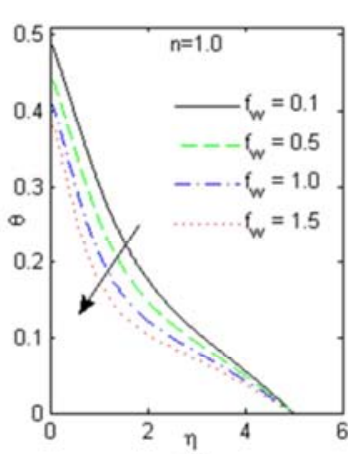

(b)

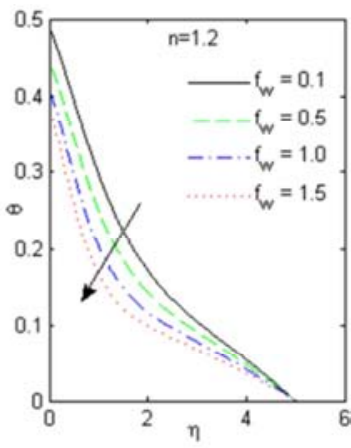

(c)

Figure 8. Temperature profiles for different values of $f_{w}$ for $E_{c}=0.5, \quad P_{r}=1.0, \quad m=1.0, \quad G_{r}=1.0, \quad r=-2.0, \quad S=0.5, \quad R_{a}=1.0, \quad B_{r}=0.5$, $M=\delta=\varepsilon=\Lambda=\Omega=0.1$.
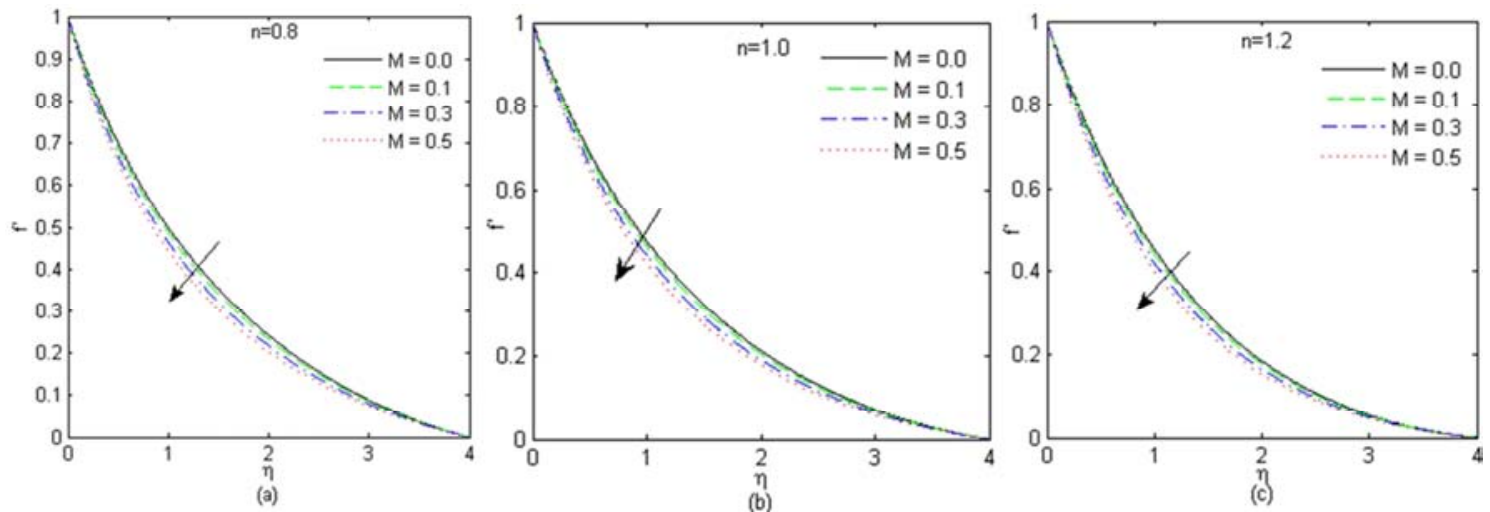

Figure 9. Velocity profiles for different values of $M$ for $E_{c}=0.5, P_{r}=1.0, m=1.0, G_{r}=1.0, r=-2.0, S=0.5, R_{a}=1.0, B_{r}=0.5, f_{w}=\delta=\varepsilon=\Lambda=\Omega=0.1$. 

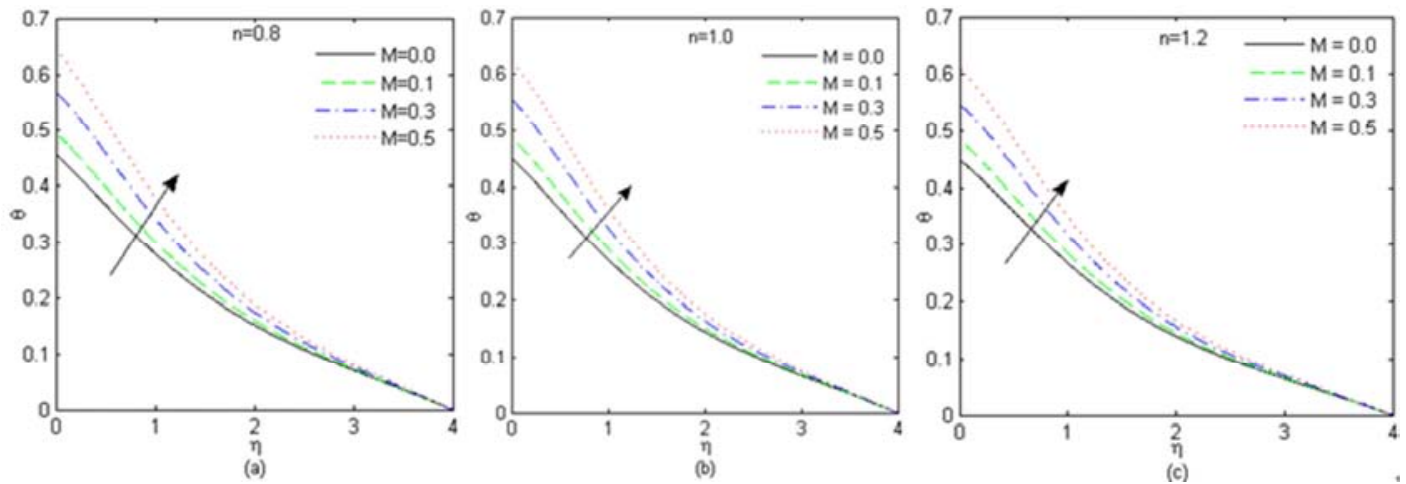

Figure 10. Temperature profiles for different values of $M$ for $E_{c}=0.5, \quad P_{r}=1.0, \quad m=1.0, G_{r}=1.0, \quad r=-2.0, \quad S=0.5, \quad R_{a}=1.0, \quad B_{r}=0.5$, $f_{w}=\delta=\varepsilon=\Lambda=\Omega=0.1$.
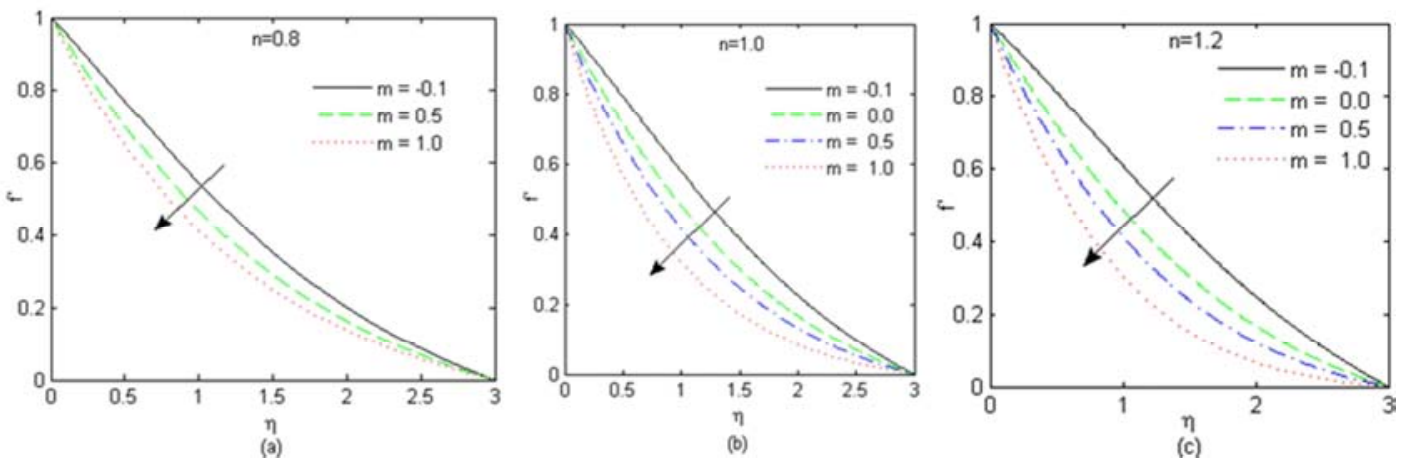

Figure 11. Velocity profiles for different values of $m$ for $E_{c}=0.05, \quad P_{r}=1.0, \quad M=0.1, \quad G_{r}=0.0, \quad r=-2.0, \quad S=0.5, \quad R_{a}=0.2, \quad B_{r}=0.5$, $f_{w}=\delta=\varepsilon=\Lambda=0.1$.
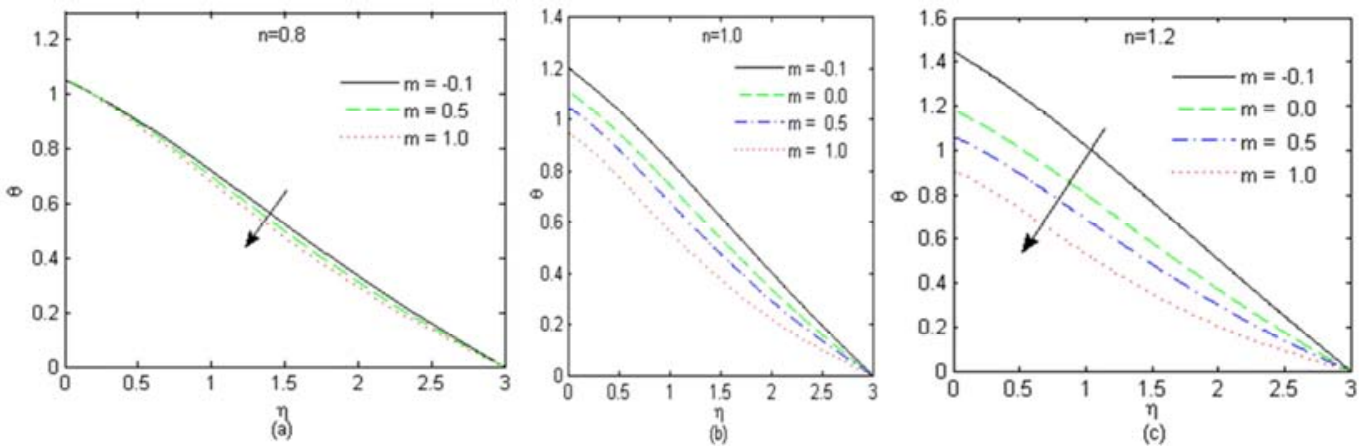

Figure 12. Temperature profiles for different values of $m$ for $E_{c}=0.05, \quad P_{r}=1.0, \quad M=0.1, G_{r}=0.0, \quad r=-2.0, \quad S=0.5, \quad R_{a}=0.2, \quad B_{r}=0.5$, $f_{w}=\delta=\varepsilon=\Lambda=\Omega=0.1$.
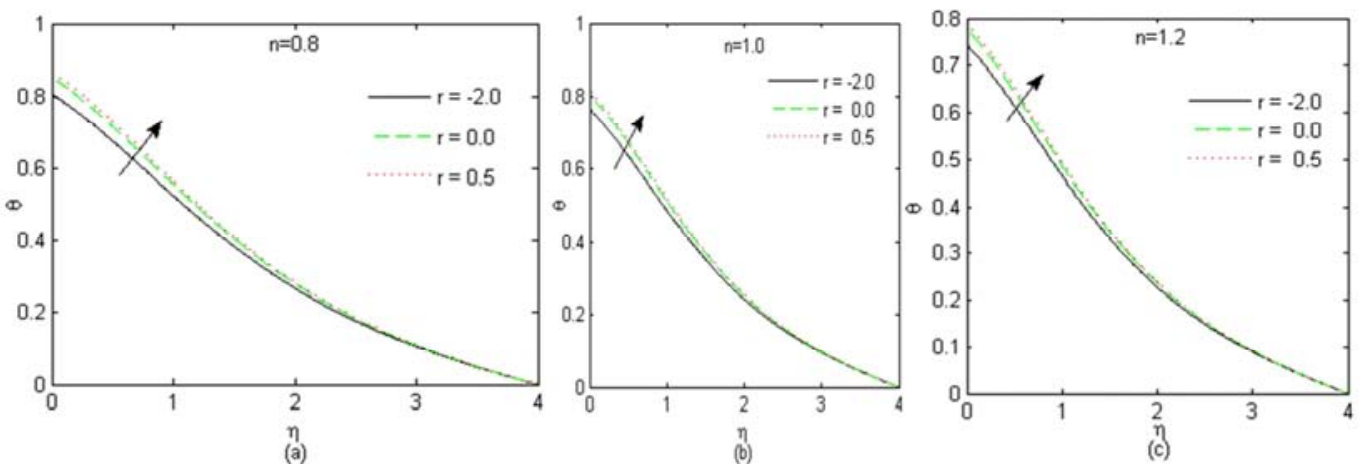

Figure 13. Temperature profiles for different values of $r$ for $E_{c}=0.5, P_{r}=1.0, \quad M=0.1, G_{r}=1.0, \quad m=1.0, \quad S=0.2, \quad R_{a}=0.3, \quad B_{r}=0.5$, $f_{w}=\delta=\varepsilon=\Lambda=\Omega=0.1$. 

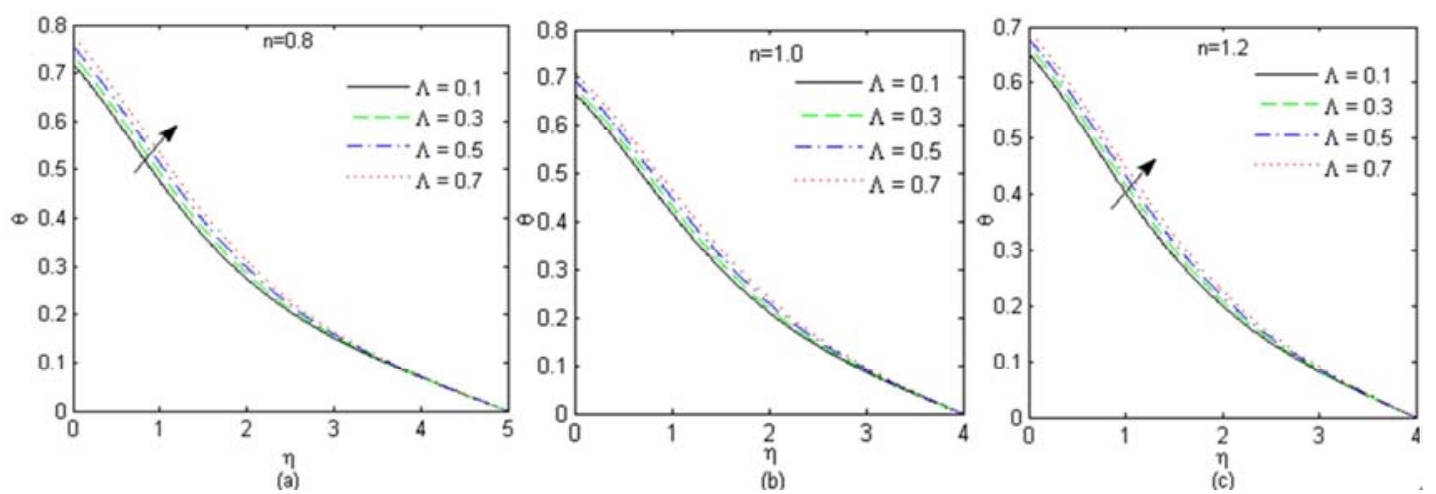

Figure 14. Temperature profiles for different values of $\Lambda$ for $E_{c}=0.5, P_{r}=1.0, M=0.1, G_{r}=1.0, m=1.0, \quad S=0.0, \quad R_{a}=0.2, r=-2.0, \quad B_{r}=0.5$, $f_{w}=\delta=\varepsilon=0.1$.
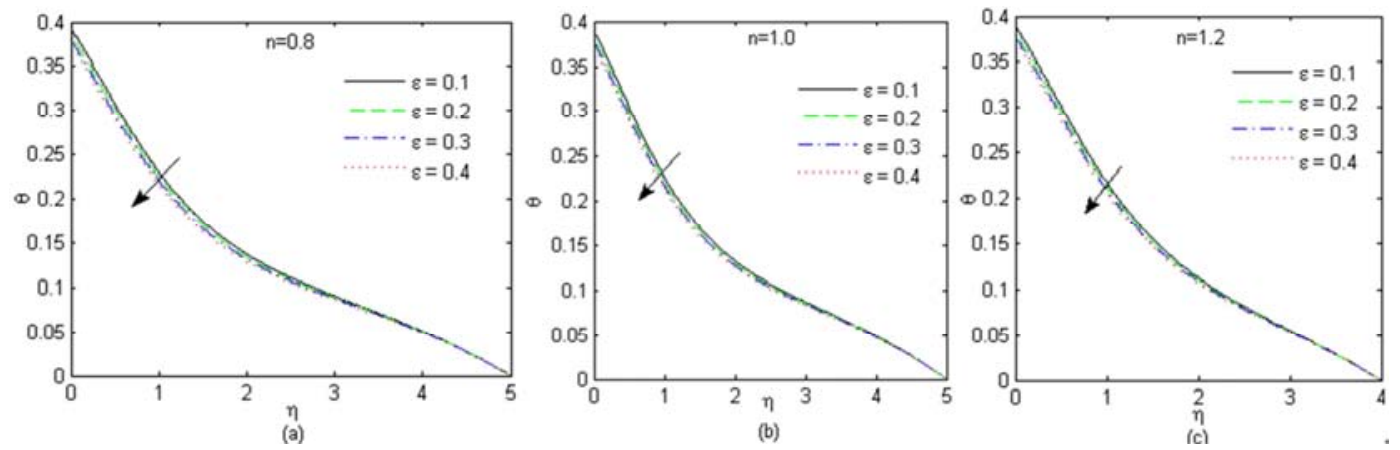

Figure 15. Temperature profiles for different values of $\mathcal{E}$ for $E_{c}=0.5, P_{r}=1.0, M=0.1, G_{r}=1.0, m=1.0, S=0.2, \quad R_{a}=1.0, r=-2.0, \quad B_{r}=0.5$, $f_{w}=\delta=\Lambda=\Omega .1$.
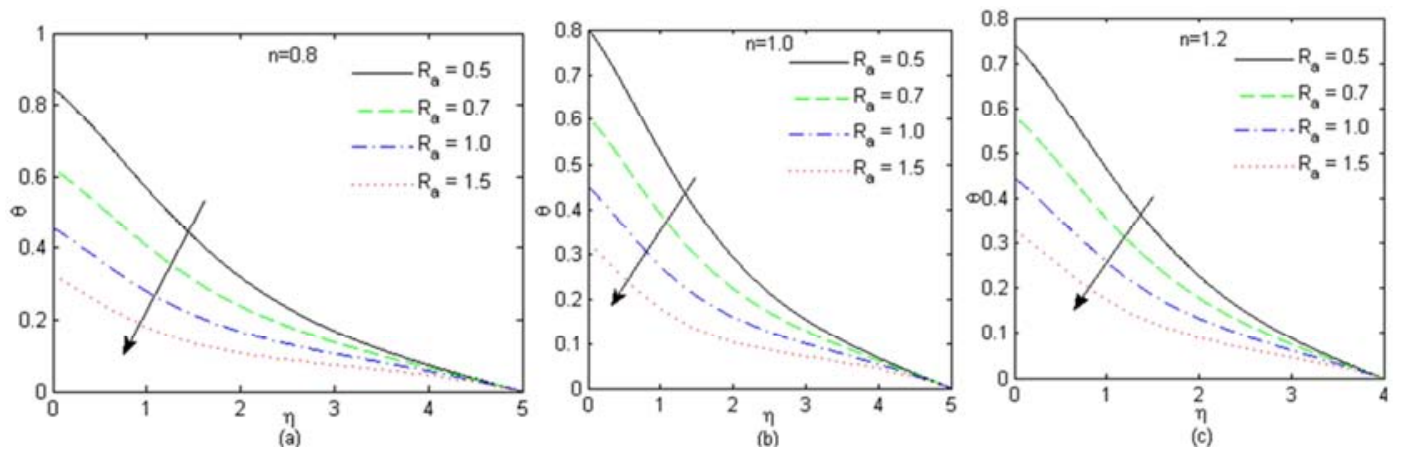

Figure 16. Temperature profiles for different values of $R_{a}$ for $E_{c}=0.5, \quad P_{r}=1.0, \quad M=0.1, \quad G_{r}=1.0, \quad m=1.0, \quad S=0.4, \quad r=-2.0, \quad B_{r}=0.5$, $f_{w}=\delta=\Lambda=\varepsilon=\Omega=0.1$.
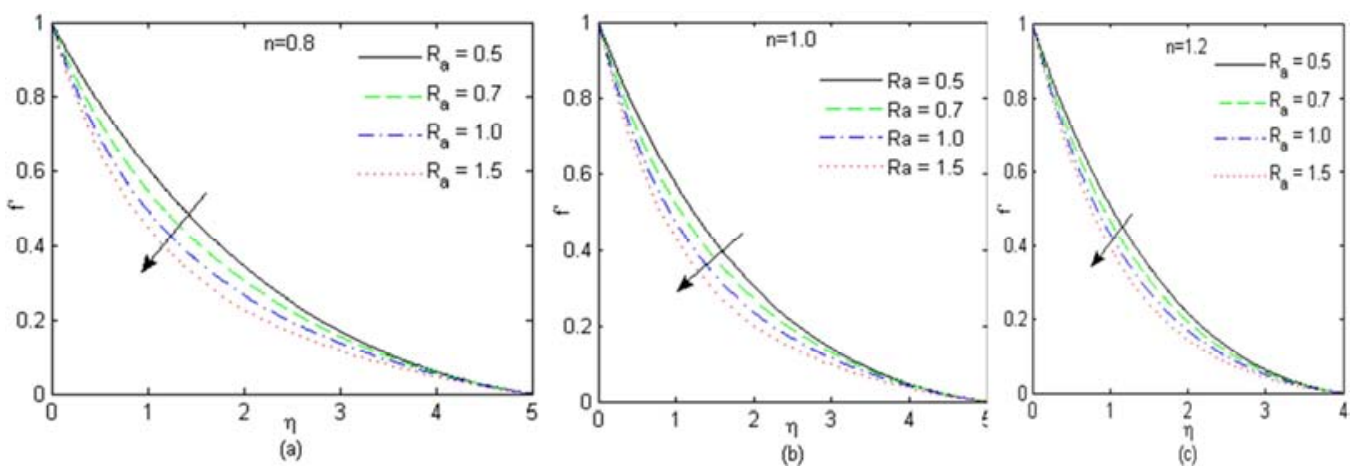

Figure 17. Velocity profiles for different values of $R_{a}$ for $E_{c}=0.5, P_{r}=1.0, \quad M=0.1, \quad G_{r}=1.0, \quad m=1.0, \quad S=0.4, \quad r=-2.0, \quad B_{r}=0.5$, $f_{w}=\delta=\Lambda=\varepsilon=\Omega=0.1$. 

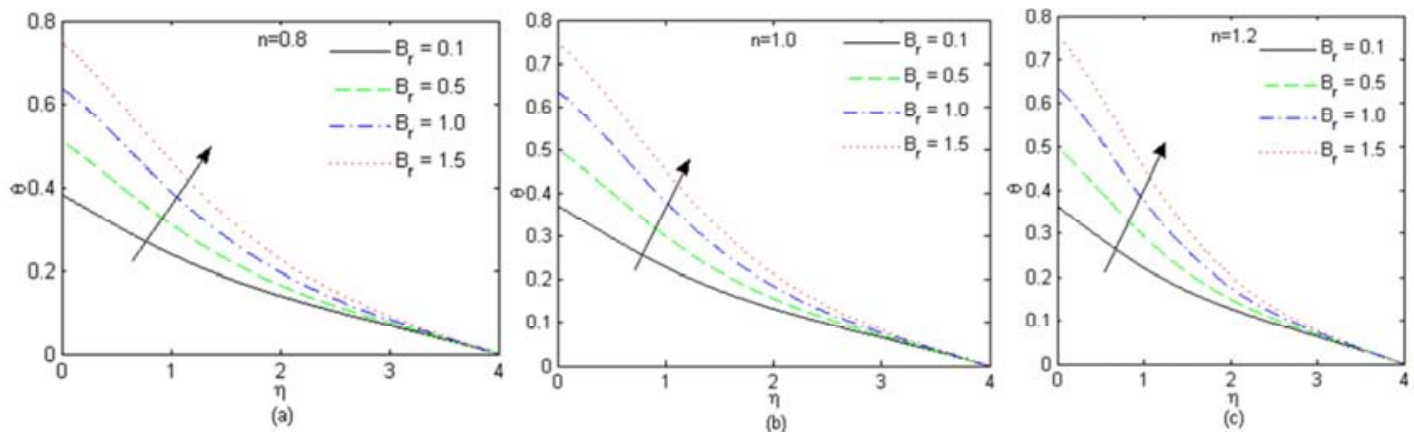

Figure 18. Temperature profiles for different values of $B_{r}$ for $E_{c}=0.5, P_{r}=1.0, \quad M=0.1, \quad G_{r}=1.0, \quad m=1.0, \quad S=0.5, \quad r=0.5, \quad R_{a}=1.0$ $f_{w}=\delta=\Lambda=\varepsilon=\Omega=0.1$.
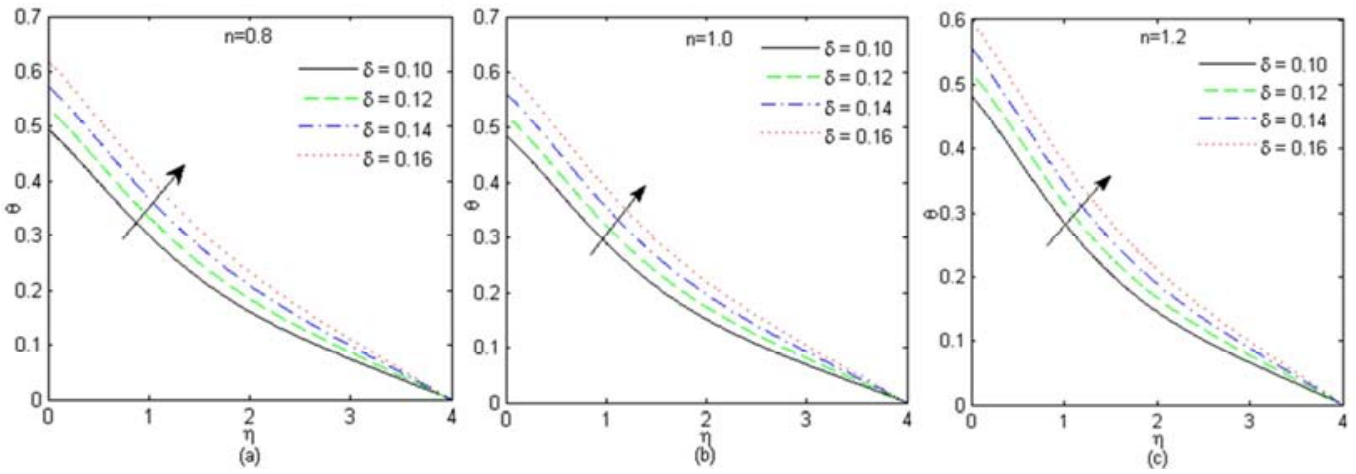

Figure 19. Temperature profiles for different values of $\delta$ for $E_{c}=0.5, P_{r}=1.0, M=0.1, G_{r}=1.0, m=1.0, B_{r}=0.5, S=0.5, r=0.5, R_{a}=1.0$ $f_{w}=\Lambda=\varepsilon=\Omega=0.1$

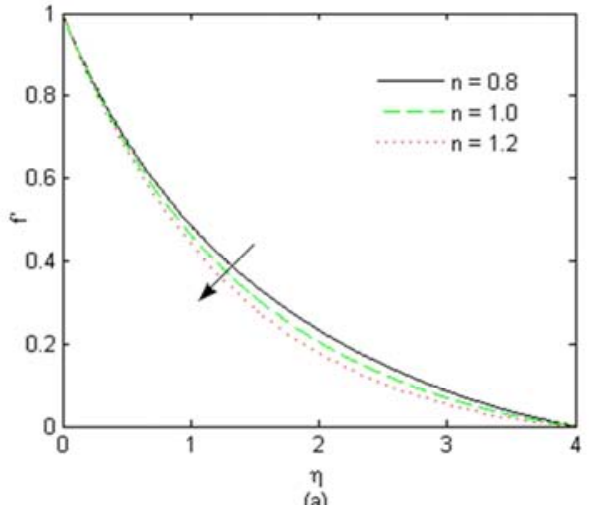

(a)

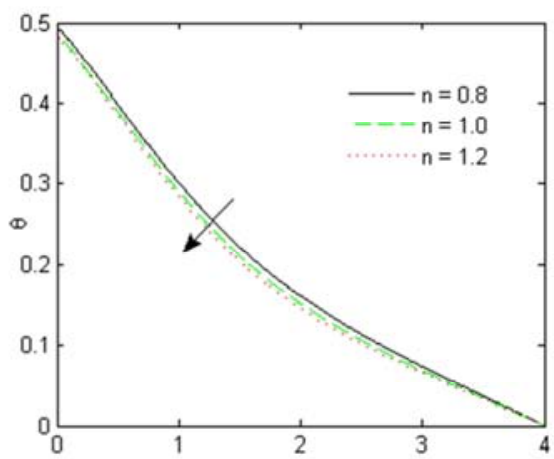

(b)

Figure 20. Velocity and Temperature profiles for different values of $n$ for $E_{c}=0.5, P_{r}=1.0, M=0.1, G_{r}=1.0, m=1.0, B_{r}=0.5, S=0.5, r=-2.0, R_{a}=1.0$ $f_{w}=\Lambda=\varepsilon=\delta=\Omega=0.1$
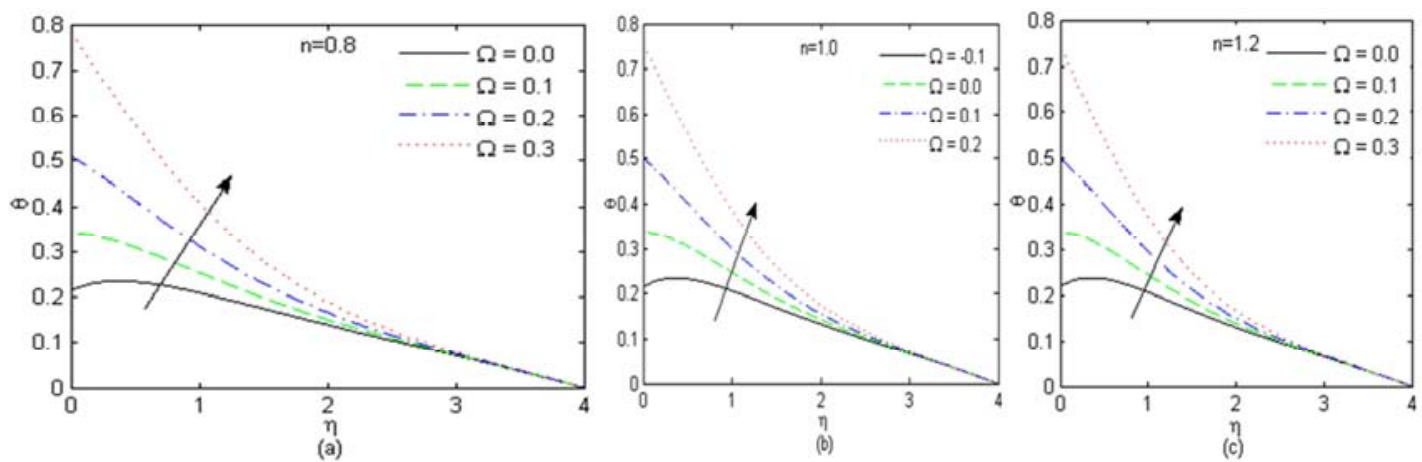

Figure 21. Velocity and Temperature profiles for different values of $\Omega$ for $E_{c}=0.5, P_{r}=1.0, M=0.1, G_{r}=1.0, m=1.0, B_{r}=0.5, S=0.5, r=0.5, R_{a}=1.0$ $f_{w}=\Lambda=\varepsilon=\delta=0.1$. 
The effect of viscous dissipation parameter $B_{r}$ is shown in Figure $18(\mathrm{a}-\mathrm{c})$. It is obvious that the temperature distribution increases as Brinkman parameter $B_{r}$ increases due to the fact that increase in viscous dissipation parameter enhances the thermal boundary layer thickness. Figure 19(a-c) shows the effect of variation in Frank-Kamenetskii parameter $\delta$ on the temperature of the fluid. A rise in the fluid temperature is observed as the Frank-Kamenetskii parameter $\delta$ increases, this is due to increase in the initial concentration of the reactant species $C_{0}$ within the flow.

Figure 20(a-b) depicts the effect of power-law index $n$ on both the velocity profiles and temperature profiles. It is observed that increase in power-law index $n$ leads to a fall in both the velocity and temperature of the fluid. It is worth noting that this complement the graphical result (figure three) shown in Ref. [18]. Figure 21(a-c) elucidates the effect of reactant consumption parameter $\Omega$ on the temperature profile. A rise in the fluid temperature is observed as the reactant consumption parameter $\Omega$ increases.

Table 1 depicts the comparison of the present study with and that of Prasad et al. [17] for the skin friction coefficient $-f^{\prime \prime}(0)$ and the results show good agreement.

Table 1. A Comparison of values of skin-friction coefficient between Prasad et al. [17] and present study with $m=1$ for different values of $n$ and $M$

\begin{tabular}{lll}
\hline & $-\boldsymbol{f}^{\prime \prime}(\mathbf{0})$ & $-\boldsymbol{f}^{\prime \prime}(\mathbf{0})$ \\
& Prasad et al. [17] & Present \\
\hline $\mathrm{n} / M$ & 0.51 .02 .0 & 0.51 .02 .0 \\
0.8 & 1.30811 .54421 .9453 & 1.31131 .54521 .9455 \\
1.0 & 1.22481 .41421 .7321 & 1.22561 .41441 .7321 \\
1.2 & 1.17491 .33301 .5959 & 1.17501 .33301 .5960 \\
\hline
\end{tabular}

Variations of values of $P_{r}, R_{a}, \mathcal{E}, E_{c}$ and $\mathrm{n}$ on the skin friction coefficient $-f^{\prime \prime}(0)$ and the rate of heat transfer $-\theta^{\prime}(0)$ at the surface are shown in Table 2. It is noticed that increasing values of $P_{r}, R_{a}, \varepsilon$ increases the skin friction coefficient and depreciates the rate of heat transfer on the surface. Also, increasing the Eckert number tends to decrease the skin friction coefficient. However, the rate of heat transfer is enhanced at the surface of the plate as the Eckert number is increased.

Table 2. Values of skin-friction coefficient and the local Nusselt number for some values of $M, P_{r}, R_{a}, \mathcal{E}$, and $E_{c}$ when $S=B_{r}=0.5$, $G_{r}=m=1.0$, $f_{w}=\Lambda=\Omega=0.1$ and $r=-2.0$.

\begin{tabular}{|c|c|c|c|c|c|c|}
\hline \multirow{2}{*}{$\boldsymbol{P}_{r}$} & \multirow{2}{*}{$\boldsymbol{R}_{a}$} & \multirow{2}{*}{$\varepsilon$} & \multirow{2}{*}{$\boldsymbol{E}_{c}$} & $\mathrm{n}=0.8$ & $\mathrm{n}=1.0$ & $\mathrm{n}=1.2$ \\
\hline & & & & $-f^{\prime \prime}(0)-\theta^{\prime}(0)$ & $-f^{\prime \prime}(0)-\theta^{\prime}(0)$ & $-f^{\prime \prime}(0)-\theta^{\prime}(0)$ \\
\hline 1.0 & 1.0 & 0.1 & 0.5 & 0.779310 .16024 & 0.786170 .15902 & 0.795920 .15853 \\
\hline 2.0 & & & & 0.938810 .13536 & 0.925540 .13443 & 0.922440 .13401 \\
\hline \multirow[t]{10}{*}{3.0} & & & & 0.999600 .12651 & 0.977490 .12569 & 0.968910 .12527 \\
\hline & 0.5 & & & 0.444410 .24248 & 0.517120 .22886 & 0.566360 .22153 \\
\hline & 0.7 & & & 0.632090 .19105 & 0.665810 .18677 & 0.692050 .18446 \\
\hline & 1.0 & & & 0.779310 .16024 & 0.786170 .15902 & 0.795920 .15853 \\
\hline & & 0.0 & & 0.765350 .16741 & 0.774850 .16574 & 0.786180 .16504 \\
\hline & & 0.1 & & 0.779310 .16024 & 0.786170 .15902 & 0.795920 .15853 \\
\hline & & 0.3 & & 0.799720 .15050 & 0.802940 .14973 & 0.810460 .14947 \\
\hline & & & 0.0 & 0.796520 .15659 & 0.800020 .15562 & 0.807510 .15534 \\
\hline & & & 0.5 & 0.779310 .16024 & 0.786170 .15902 & 0.795920 .15853 \\
\hline & & & 0.7 & 0.772330 .16175 & 0.780550 .16041 & 0.791230 .15984 \\
\hline
\end{tabular}

\section{Conclusions}

In this paper, the effect of thermo-physical parameters on free convective flow of a chemically reactive power law fluid driven by exothermal plate in the presence of thermal radiation and suction has been investigated. The reduced coupled system of non-linear ODEs was solved numerically. The velocity of the fluid decreases with the increase in the values of the power-law index $n$, velocity exponent parameter $\mathrm{m}$, magnetic parameter $\mathrm{M}$, radiation parameter $R_{a}$ and suction parameter $f_{w}$ while increase in velocity is noted as the Grashof number $G_{r}$ increases. Also, the temperature in the boundary layer flow rises with increase in thermal conductivity parameter $\Lambda$, magnetic parameter $M$, Eckert number $E_{c}$, Frank-Kamenetskii $\delta$, activation energy parameter $\varepsilon$, the Brinkman number $B_{r}$ and reactant consumption parameter $\Omega$ while the fluid temperature reduces with larger values of Grash of number $G_{r}$ powerlaw index n, velocity exponent parameter $\mathrm{m}$, Prandtl number $P_{r}$, radiation parameter $R_{a}$, and local suction parameter $f_{w}$. The heat transfer rate enhances with increase in Eckert number $E_{c}$ while it reduces for Prandtl number $P_{r}$, radiation parameter $R_{a}$, activation energy parameter $\varepsilon$, Eckert number $E_{c}$.

\section{Nomenclature}

$\begin{array}{ll}A & \text { reactant } \\ B & \text { product species } \\ B_{0} & \text { magnetic field strength } \\ B_{r} & \text { Brinkmann number } \\ c_{p} & \text { specific heat capacity } \\ C & \text { concentration }\end{array}$




\section{Greek Symbol}

$\beta \quad$ thermal expansion coefficient

$\delta \quad$ Frank-Kamenetskii parameter

$\varepsilon \quad$ activation energy parameter

$\eta \quad$ dimensionless similarity variable

$\theta$ dimensionless temperature

$\mu \quad$ dynamic viscosity

$\Lambda \quad$ thermal conductivity parameter

$\Omega \quad$ reactant consumption parameter

$\rho \quad$ fluid density

$\psi \quad$ stream function

\section{Subscripts}

$\begin{array}{ll}w & \text { wall } \\ \infty & \text { free stream }\end{array}$

\section{References}

[1] Quoc-Hung Nguyen, and Ngoc-Diep Nguyen, "Incompressible non-Newtonian fluid flows," Continuum Mechanics - Progress in Fundamentals and Engineering Applications, Dr. Yong Gan (Ed.), ISBN: 978-953-51-0447-6, InTech, 2012, pp. 47-72.

[2] Yinwei Lin, and C. K. Chen, "Analyzing irreversibility of heat transfer for a non-Newtonian power-law flow with power-law temperature using differential transform method," Academia Journal of Agricultural Research, Vol. 5, No. 11, November 2017, pp. 577-586.

[3] K. Kalyani, K. Sreelakshmi, and G. Sarojamma, "Effect of thermal radiation on the Casson thin liquid film flow over a stretching sheet," Global Journal of Pure and Applied Mathematics, Vol. 13, No. 6, 2017, pp. 1575-1592

[4] Kho Yap Bing, Abid Hussanan, Muhammad Khairul Anuar Mohamed, Norhafizah Mohd Sarif, Zulkhibri Ismail and Mohd Zuki Salleh, "Thermal radiation effect on MHD flow and heat transfer of Williamson nanofluids over a stretching sheet with Newtonian heating," American Institute of Physics, AIP Conf. Proc. 1830, 020022 (2017).

[5] T. Hayat, Z. Iqbal, M. Mustafa, and A. A. Hendi, "Melting heat transfer in the stagnation-point flow of third grade fluid past a stretching sheet with viscous dissipation," Thermal Science, Vol. 17, No. 3, 2013, pp. 865-875.

[6] A. Acrivos, "A theoretical analysis of laminar natural convection heat transfer to Non-Newtonian fluids," The American Institute of Chemical Engineers Journal, Vol. 6, No. 4, 1960, pp. 584-590.

[7] C. Tien, "Laminar natural convection heat transfer from vertical plate to power-law fluid" Applied Scientific Research Vol. 17, No. 3,1967 pp. 233-248.

[8] A. Som and J. L. S. Chen, "Free convection of non-Newtonian fluids over non-isothermal two-dimensional bodies," International Journal of Hear and Mass Transfer, Vol. 27, No. 5, 1984, pp. 791-794.

[9] S. Bhowmick, and M. M. Molla, "Shear rates calculation on natural convection of non-Newtonian fluid over a horizontal circular cylinder with uniform surface heat fluxes," Journal of Presidency University, Part: B, Vol. 2, No. 2, 2013, pp. 64-77.

[10] Gabriella Bognár, Imre Gombkötı, and Krisztián Hriczó, "Power-law non-Newtonian fluid flow on an inclined plane," International Journal of Mathematical Models and Methods in Applied Sciences, Vol. 6, No. 1, 2012, pp. 72-80.

[11] Asterios Pantokratoras, "Natural convection over a vertical isothermal plate in a non-Newtonian power-law fluid: New results," Advances in Mechanical Engineering, Vol. 8, No. 5, 2016, pp. 1-12.

[12] B. I. Olajuwon, "Flow and natural convection heat transfer in a power law fluid past a vertical plate with heat generation," International Journal of Nonlinear Science, Vol. 7, No. 1, 2009, pp. 50-56.

[13] K. B. Pavlov, "Magnetohydrodynamic flow of an incompressible viscous fluid caused by deformation of a plane surface," Magnitnaya Gidrodinamika, Vol. 4, 1974, pp. 146-147.

[14] R. M. Darji, and M. G. Timol, "Similarity treatment for MHD free convective boundary layer flow of a class of nonNewtonian fluids," FME Transactions, Vol. 44, No. 2, 2016, 197-203.

[15] A. Shahzad, and R. Ali, "MHD flow of a non-Newtonian power law fluid over a vertical stretching sheet with the convective boundary condition," Walailak Journal of Science and Technology, Vol. 10, No. 1, 2013, pp. 43-56.

[16] J. Ahmed, A. Begum, A. Shahzad, R. Ali, "MHD axisymmetric flow of power-law fluid over an unsteady stretching sheet with convective boundary conditions" Results in Physics, Vol. 6, 2016, pp. 973-981.

[17] K. Prasad, S. Santhi, and P. Datti, "Non-Newtonian power-law fluid flow and heat Transfer over a non-linearly stretching surface, “Applied Mathematics,” Vol. 3, No. 5, 2012, pp. 425-435. 
[18] Naikoti Kishan, and P. Kavitha, "MHD non-Newtonian power law fluid flow and heat transfer past a non-linear stretching surface with thermal radiation and viscous dissipation," Journal of Applied Science and Engineering, Vol. 17, No. 3, 2014, pp. 267-274.

[19] K. Saritha, M. N. Rajasekhar, and B. Shashidar Reddy, "Radiation effects on MHD non-Newtonian power-law fluid past over a non-linearly stretching surface with viscous dissipation," International Journal of Applied Engineering Research, Vol. 11, No. 4, 2016, pp. 2729-2736.

[20] A. W. Ogunsola, and B. A. Peter, "Effect of thermal radiation on unsteady gravity flow of a power-law fluid with viscous dissipation through a porous medium," IOSR Journal of Computer Engineering, Vol. 16, No. 4, 2014, pp. 18-23.

[21] Aftab Ahmed, Javed I. Siddique, and Muhammad Sagheer, "Dual solutions in a boundary layer flow of a power law fluid over a moving permeable flat plate with thermal radiation, viscous dissipation and heat generation/absorption," Fluids, Vol. 3, No. 6, 2018, pp. 1-16.

[22] D. J. Samuel, "Chemical reaction and melting heat effects on MHD free convective radiative fluid flow past a continuous moving plate in the presence of thermo-physical parameters," Defect and Diffusion Forum, Vol. 384, 2018, pp. 80-98.
[23] N. Khan, T. Mahmood, M. Sajid, and M. S. Hashmi, "Heat and mass transfer on MHD mixed convection axisymmetric chemically reactive flow of Maxwell fluid driven by exothermal and isothermal stretching disks," International Journal of Heat and Mass Transfer, Vol. 92, 2016, pp. 10901105.

[24] Kh. Abdul Maleque, "Effects of exothermic/endothermic chemical reactions with Arrhenius activation energy on MHD free convection and mass transfer flow in presence of thermal radiation," Journal of Thermodynamics, 2013, Article ID 692516, 11 pages.

[25] A. C. Cogley, W. G. Vincenti, and S. E. Giles, "Differential approximation for near equilibrium flow of a non-gray gas," American Institute of Aeronautics and Astronautics, Vol. 6, 1968, pp. 551-553.

[26] J. Merkin, and T. Mahmood, "Convective flows on reactive surfaces in porous media," Transport in Porous Media, Vol. 47, 1998, pp. 279-293. 